\title{
A CUSTOMIZAÇÃO EM MASSA NA CONSTRUÇÃO CIVIL: UM ESTUDO NO SUBSETOR DE EDIFICAÇÕES
}

\section{THE MASS CUSTOMIZATION IN THE BUILDING CONSTRUCTION: A STUDY ON CONSTRUCTIONS SUBSECTOR}

\author{
João Tomé de Araujo Filho \\ Mestrado em Engenharia de Produção \\ PPGEP - UFPb \\ Engenheiro Eletrônico \\ Rua Alexandrino Cavalcante, 90 - Apt. 10 - Campina Grande (PB) \\ Tel: (83) 3322.5000 - email: clubemdm@ hotmail.com \\ Maria de Lourdes Barreto Gomes \\ Professora Universitária \\ Doutorado em Engenharia de Produção - UFSC \\ Economista \\ CT - Bloco G - Campus Universitário - UFPb - João Pessoa (PB) \\ Tel: (83) 3216.7813 - email: marilu@ct.ufpb.br
}

\begin{abstract}
RESUMO
Este artigo aborda a utilização da estratégia de customização em massa na construção civil, subsetor edificações, em que elementos da produção convencional convivem, no mesmo canteiro de obras, com elementos da produção customizada; e objetiva verificar como se dá este processo de customização e qual o seu reflexo na cadeia de suprimentos. Verifica também a aplicação da estratégia de postponement como condição necessária ou agente facilitador no sentido de prover um produto o mais adequado possível às expectativas de cada comprador. O subsetor de edificações é um dos mais importantes da economia e seus reflexos vão além de um simples produto imobiliário. Como se sabe, a importância e o impacto desta atividade sobre o ambiente econômico permeiam toda a cadeia produtiva. Os instrumentos utilizados foram a pesquisa bibliográfica e a pesquisa de campo. Esta última, realizada em três edifícios residenciais, na cidade de Campina Grande, Paraíba. Os resultados estão relacionados aos aspectos que contribuem para o novo enfoque e ao ponto de desacoplamento, a partir do qual as especificações do cliente são levadas em conta no processo construtivo. Verificou-se que elementos só recentemente encontrados na literatura já se fazem presentes nas edificações pesquisadas.
\end{abstract}

Palavras-chave: customização em massa, personalização, construção civil, cadeia de suprimentos, SCM.

\begin{abstract}
This paper discusses the use of mass customization strategy in constructions, especially in the subsection of buildings. This study aims to verify how this process of mass customization and its reflection in the supply chain happen. It also verifies the application of the techniques of
\end{abstract}


postponement as a prerequisite or facilitator agent in order to provide a product with the best possible expectations of each customer. The instruments used were a bibliographical search and field research (exploratory and explanatory). The last, held in three residential buildings, in the city of Campina Grande, Paraíba. The main results are related to aspects that contribute to the new focus, the point of decoupling from which the customer's specifications are included in the constructive process. Elements early present in literature were identified in the enterprises studied.

Key-words: mass customization, personalization, building construction, supply chain, SCM.

\section{INTRODUÇÃO}

Foi a Revolução Industrial dos séculos XVIII e XIX que marcou o início da produção industrial moderna, com o uso intensivo das máquinas e a criação das fábricas. Por sua vez, coube à produção em massa, iniciada na segunda metade do século XIX e aperfeiçoada por Ford e Sloan na indústria automobilística americana, o impulso para o extraordinário crescimento industrial e econômico verificado ao longo do século XX. Para Graeml (1998), no entanto, a Revolução Industrial e o conceito de produção em massa levaram as empresas praticamente a esquecer que os clientes tinham necessidades individualizadas e desejos distintos uns dos outros.

No entanto, a acirrada competição a que foram submetidas as organizações nos últimos anos, contribuiu para levá-las a buscar novos enfoques e estratégias, na tentativa de encontrar soluções para suas crises, manter ou aumentar participação em seus respectivos mercados, ou, ainda, abrir novos caminhos e oportunidades. Estes fatores e mudanças, aliados a novas tecnologias, permitiram se produzir em massa e, ao mesmo tempo, atender aos desejos, necessidades e preferências individuais dos clientes. Surgia assim uma nova tendência: a customização em massa. Na concepção de Frutos (2000, p. 13), a implementação da customização em massa "é uma tarefa complexa e intrigante que envolve a solução de um paradoxo: produzir à maneira da produção em massa e tratar os clientes de forma individual”. Para muitos autores, todavia, esta estratégia deve se tornar o novo paradigma da produção.

Como capacidade tecnológica, a customização em massa foi antecipada em 1970 por Alvin Toffler em seu livro "Choque do Futuro", onde descreveu as oportunidades que as modernas tecnologias de manufaturas flexíveis iriam proporcionar (PILLER; KUMAR, 2006). Seu início, na verdade, começou com a segmentação de mercados. De fato, a estratégia de segmentação de mercados baseada nas preferências dos consumidores mostrou-se eficiente 


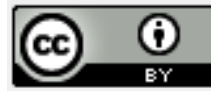

por mais de meio século (KUMAR, 2008; SVENSSON; BARFOD, 2002). Os anos 80 testemunharam uma segmentação ainda maior, em que nichos de mercado passaram a ser o alvo dos esforços empresariais. Finalmente, o desenvolvimento de novas tecnologias, flexibilidade de processos e de tratamento de informações, permitiu a customização dos mercados (DAVIS, 1987).

A customização em massa se baseia na noção de economia de escopo, onde avanços na tecnologia de manufatura e de informação, bem como novos métodos de gerenciamento, tem permitido a muitas indústrias a entrega de produtos customizados através da flexibilidade e rápida responsividade (KOTHA, 1996). Ela visa combinar os ganhos da produção em massa com o diferencial da produção artesanal ou sob encomenda (HART, 1995). De fato, Lampel \& Mintzberg (1996) dizem ser a customização em massa um meio-caminho entre estes dois tipos de produção, e Svensson \& Barfod (2002) defendem que a customização em massa tem permitido a entrega de produtos customizados a preços compatíveis com os padronizados.

O ramo da construção civil vem experimentando mudanças a partir da modificação do perfil de seus clientes. Em termos de mercado, o processo se iniciou como resposta às demandas dos clientes de maior poder aquisitivo, naturalmente mais exigentes. Depois se expandiu como reação à preocupação com o fator qualidade e pela própria evolução do padrão de consumo da sociedade em geral (BRANDÃO, 1997 apud FRUTOS, 2000). A construção civil, como atividade, é parte indissociável do desenvolvimento do país, gerando bens que, além de produzir a infra-estrutura necessária para diversas atividades econômicas, proporcionam bem-estar e qualidade de vida à sociedade, sendo inadmissível analisar a indústria da construção civil como atividade fim isolada, de acordo com os conceitos mais recentes advindos da economia industrial (JOBIM FILHO; JOBIM; ESTRADA, 2002).

Estes modernos conceitos abordam a ideia de desenvolvimento de cadeias de suprimentos, também chamadas por diversos autores de cadeias produtivas ou cadeias de valor (Supply Chain). Para Mentzer et al (2001, p. 4), cadeia de suprimentos pode ser definida como "uma configuração de três ou mais entidades (organizações ou indivíduos) diretamente envolvidas no fluxo, à montante ou à jusante, seja de produtos, serviços, finanças ou informações, de uma fonte para o consumidor". Definição semelhante é dada por Svensson (2002), para quem uma cadeia de suprimentos é um sistema por meio do qual empresas e organizações interligadas entregam produtos e serviços a seus consumidores. Essa rede de organizações é flexível, dinâmica e complexa (SIMCHI-LEVI, D.; KAMINSKY; SIMCHI- 
LEVI, E., 1999). O novo enfoque, que busca atender critérios individualizados, incorpora mudanças na cadeia de suprimentos das construtoras, e, consequentemente, na logística de materiais, para permitir uma abrangência bem maior em relação às opções disponibilizadas aos clientes.

A construção civil, como se sabe, utiliza uma diversidade de insumos, materiais ou componentes em quantidades tais que chegam a milhares de itens. Além disso, cada etapa do processo utiliza determinados insumos e seus derivados, em fases cronológicas distintas e dentro de um cronograma de produção que pode ou não depender de outros processos. Quando acrescentada a possibilidade de customização das unidades residenciais de acordo com critérios individuais, fica explícita a extrema complexidade na gestão da cadeia de suprimentos necessária para lidar com todos estes elementos simultaneamente (MAIA, 2004). Estes insumos, materiais e componentes vem de várias fontes. A aplicação ou utilização deles pode envolver parcerias, subcontratação e terceirização. Dessa forma, decoradores e arquitetos, indicados pelos clientes, podem precisar compartilhar informações com engenheiros de obras.

Zegarra, Frigieri e Cardoso (1999, p.2) abordam este aspecto, quando identificam que um dos principais problemas que a cadeia de suprimentos da construção imobiliária enfrenta é o seu alto grau de fragmentação:

[...] outro caso de fragmentação no setor ocorre entre os diversos participantes ou agentes da cadeia produtiva. Na indústria da construção civil existem inúmeras empresas de diversos ramos, quais sejam: fornecedores de materiais, fornecedores de mão-de-obra, fornecedores de serviços, fornecedores de projetos e engenharia. Cada um deles agrupa empresas com estruturas distintas, mas todas apresentam como objetivo comum entregar algum produto ou serviço que seja necessário para o processo de construção como um todo.

Durante os últimos anos, as empresas investiram agressivamente recursos e esforços com o objetivo de reduzir seus custos operacionais, visualizando a eficiência interna como geradora de benefícios, e acreditando que as melhores oportunidades agora residem na melhoria da coordenação com seus fornecedores e distribuidores (FISHER, 1997).

A customização de produtos imobiliários, portanto, exige uma transformação estrutural das empresas, exigindo, prioritariamente, o investimento em projetos, processos construtivos, administração, tecnologia da informação e de materiais e a capacitação de colaboradores internos e externos para otimização de toda a cadeia de suprimentos (MAIA, 2004). A importância do gerenciamento deste fluxo de suprimentos durante a administração da obra decorre de seu impacto direto nos custos e na qualidade da construção em geral (FONTANINI, 2004). A fim de estudar este fenômeno, este trabalho faz um levantamento no 
segmento da construção civil voltado para a construção de edifícios residenciais (condomínios verticais) na cidade de Campina Grande, Estado da Paraíba, e busca identificar os procedimentos implementados pelas construtoras para fazer frente ao novo enfoque mercadológico, objetivando:

- Analisar o processo de customização em massa utilizado no subsetor de edificações com foco na gestão da cadeia de suprimentos;

- Averiguar quais elementos são customizados nas edificações;

- Descrever como se dá o processo de customização;

- Identificar os aspectos que contribuem para a customização no processo construtivo.

Foi realizada uma pesquisa qualitativa, caracterizada como exploratória, explicativa e descritiva. Isto porque as principais finalidades foram: (a) trazer maior conhecimento a respeito da customização em massa, tornando este tema mais claro; (b) tornar algo inteligível; no caso, a estratégia de customização em massa, esclarecendo quais fatores contribuem para a ocorrência deste fenômeno; e, (c) descrever as características dos fenômenos observados (GIL, 1996; VERGARA, 2004). Os meios utilizados foram a pesquisa bibliográfica e a pesquisa de campo.

Para participação na pesquisa, se buscou empresas que atuassem no subsetor de edificações de edifícios residenciais na cidade de Campina Grande, Estado da Paraíba. A cidade concentra o segundo maior mercado imobiliário do Estado e reconhecidamente um dos maiores do interior do Nordeste. Seu processo de verticalização iniciou-se nos anos 50 e foi um dos primeiros em cidades do interior. No entanto, só a partir dos anos 90 que este processo se acelerou de maneira significativa. Foram escolhidos três empreendimentos de construtoras diferentes (estudo multicaso). A coleta de informações foi efetivada através da aplicação de questionários estruturados, entrevistas estruturadas e roteiro de observações, realizados com os engenheiros de obras, sujeitos da pesquisa, que também eram responsáveis pela interface com o cliente e pela aquisição dos materiais para a customização. As empresas, e seus respectivos empreendimentos, são identificados no trabalho pelas letras A, B e C. 


\section{REFERENCIAL TEÓRICO}

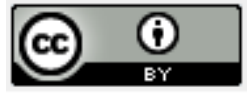

O referencial teórico, desenvolvido neste item, está baseado em dois temas principais: a estratégia de postponement e a customização em massa no subsetor de edificações.

\subsection{Postponement}

Postponement é uma estratégia logística capaz de possibilitar às empresas agilidade e flexibilidade em suas cadeias de suprimentos, visando a redução de custos com perdas e manutenção de estoques. Foi um conceito visionário desenvolvido nos anos 50, como uma ferramenta de aplicação potencial no mundo empresarial (WALLER; DABHOLKAR; GENTRY, 2000). Ela baseia-se no retardo dos movimentos e na formulação final dos produtos até que se tenha informação da demanda (CUNHA, 2002). Segundo Van Hoek (1998) este retardo na configuração dos produtos deve ocorrer sempre que possível. Em casos extremos, até mesmo operações de manufatura devem ser transferidas para os canais de distribuição ou mesmo para o consumidor final.

Como prática no gerenciamento da cadeia de suprimentos, o postponement objetiva facilitar e prover a customização dos produtos sem que haja perdas dos benefícios advindos da economia de escala, além de ser uma forma eficaz de lidar com variações de demanda e de possibilitar entregas mais rápidas e confiáveis. Os custos decorrentes dos riscos e incertezas estão diretamente ligados à intensidade de diferenciação (de forma, tempo e lugar) que ocorre com os produtos, durante os processos de manufatura e logística (PAGH; COOPER, 1998). Lee \& Tang (1997) afirmam que a remodelagem do produto e do processo, visando retardar o ponto de diferenciação do produto, aumenta a flexibilidade do processo para lidar com as variações do mercado.

O postponement pode ser implementado de várias formas: no atraso das atividades de processamento ou montagem dos produtos, no retardo do transporte ou, até mesmo, por mudanças no esquema de distribuição. Desta forma pode-se manter estoques centralizados aguardando o pedido dos clientes ou dos depósitos regionais. Algumas atividades finais que agregam valor ao produto podem ser separadas, em termos de localização e de tempo, das outras atividades de fabricação. Estas, por sua vez, se concentram na manufatura de produtos genéricos, em larga escala. Assim se diminui a incerteza na previsão da demanda de muitos produtos variados para poucos produtos padronizados. 


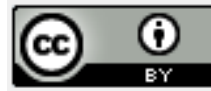

A implicação prática do postponement é que operações de fabricação, transporte e diferenciação de produtos devem ser retardadas, sempre que possível, sendo realizadas apenas quando solicitadas. É, portanto, um sistema de operações que se opõe ao sistema de produção empurrada tradicional, em que produtos são feitos para estoque, independente do pedido do cliente. O postponement é, dessa forma, um sistema de produção puxada, onde as atividades são desencadeadas somente depois que o cliente efetua seu pedido. Com isso, é possível proporcionar, ao mesmo tempo, customização e redução de custos. Este último, como conseqüência da redução de transporte e de estoques de materiais (HAMZAGIC, 2003).

Uma das formas de medir o nível de postponement é através da verificação do Decoupling Point (DP), também chamado de ponto de desacoplamento, que é o ponto do processo de produção onde o consumidor exerce sua influência direta, ou seja, onde o cliente entra com as especificações individualizadas que serão levadas em conta na produção (MELO; EULÁLIA; BREMER, 2000).

Neste ponto, a customização dos produtos deve ser separada do processo primário de manufatura das matérias-primas. Esta separação possibilita que o processo primário seja feito de forma convencional, com o foco na produtividade e nos baixos custos (economia de escala), resultando em produtos padronizados; enquanto que as atividades finais se concentram na customização (diferenciação) e entrega dos produtos.

No contexto prático do postponement, os processos anteriores ao DP são admitidos menos críticos e podem ser conduzidos pela abordagem tradicional de estratégia de produção (ALFNES; STRANDHAGEN, 2000). A postergação da diferenciação do pedido permite às empresas serem mais eficientes em custo, mas à medida que o DP se posiciona à jusante, menor é o grau de customização do produto oferecido ao cliente.

\subsection{A customização em massa no subsetor de edificações}

Vários são os fatores que podem determinar a escolha e a decisão de compra de uma unidade residencial. Estes fatores são independentes do projeto em si e dizem respeito à localização, características do ambiente, preço, condições de pagamento e financiamento, etc.; de forma que a realidade espacial da habitação se torna um fator de importância secundária. Por outro lado, o ambiente interior em si é precisamente o bem de consumo que é comprado e vendido (BRANDÃO, 2002b) e precisa ser adaptado ao gosto e necessidade do comprador. 
Para Brandão (2002b), mudanças sócio-demográficas diversas, como modificações na estrutura e nos arranjos familiares e possibilidade de trabalho em casa (home-office) tem trazido novas funções e atividades, alternadas ou sobrepostas, que precisam ser exercidas dentro do ambiente onde se mora, demandando flexibilidade e customização deste ambiente.

É no subsetor de edificações, especialmente de edifícios residenciais, que tem surgido a possibilidade de customização das unidades residenciais a partir da modificação da plantapadrão. Segundo Frutos (2000), a personalização de produtos é uma estratégia de competitividade cada vez mais utilizada pelas empresas, mas ainda incipiente no setor de construção de condomínios residenciais. Esta tendência, no entanto, tem mudado e se fortalecido nos últimos anos, conforme já visto neste trabalho. Ela surgiu a partir da percepção do comportamento dos consumidores, notadamente daqueles de maior poder aquisitivo.

Era comum o cliente receber um apartamento novo e acabado e imediatamente promover nele uma reforma abrangente, segundo seus critérios individuais de beleza, estética ou conforto. Da mesma forma, também era comum a tentativa de clientes, ao adquirir imóveis na planta, de interferir no layout ou opinar em detalhes de acabamentos, cores, materiais, formatos, etc. A partir desta constatação, as construtoras implementaram a possibilidade dos clientes efetuarem mudanças nos projetos.

Esta interferência pode se dar em várias fases da obra e de maneiras diferentes, através da flexibilidade arquitetônica. Para Santana, Oliveira \& Meira (2007), a flexibilização surge como uma ferramenta que vem integrar-se ao processo de personalização, uma vez que sempre ocorre alguma intervenção nos projetos originais.

Brandão \& Heineck (1997), identificam quatro formas de flexibilidade arquitetônica capazes de promover a adaptação do espaço de moradia:

- flexibilidade inicial: obtida pela variabilidade dos produtos, na fase de construção, e de interesse do primeiro usuário;

- flexibilidade contínua (ou posterior, ou funcional): se dá ao longo da vida útil da habitação;

- flexibilidade permitida (personalização): ocorre quando apenas uma opção é dada ao cliente, seja de layout ou de acabamentos, atendendo aos pedidos viáveis de modificação de projeto; 
- flexibilidade planejada: ocorre quando, na etapa de projeto, já são criadas mais de uma opção ao cliente para sua escolha no ato da compra.

Em pesquisa efetuada em várias cidades brasileiras, estes autores classificaram as formas de flexibilidade oferecidas em apartamentos em quatro grupos distintos:

- grupo 1: empreendimento com vários apartamentos-tipo. Ocorre quando um mesmo empreendimento oferece várias plantas diferentes (unidades-tipo). Isto pode ser entendido como uma forma de flexibilidade, pelo fato do cliente ter opções de escolha, embora a localização das plantas seja pré-definida. Em obras deste tipo, normalmente não são admitidas mudanças internas em cada apartamento devido à complexidade arquitetônica já existente. Pode-se dizer que este tipo de flexibilidade envolve um aspecto macro do empreendimento, uma vez que nessa concepção, não há interesse da empresa construtora em modificar ou adaptar as unidades em suas características internas;

- grupo 2: oferta de vários layouts para o mesmo apartamento-tipo. Neste caso, o cliente pode fazer a opção entre vários layouts internos. Esta oferta pode ocorrer de três formas: (1) apresentando as alternativas para cada setor sem, no entanto, desenhar layouts inteiros; (2) apresentando vários layouts sem que nenhum deles seja considerado opção padrão, principal ou básica; e, (3) fixando as áreas molhadas e propondo diversas combinações para os cômodos das áreas secas, ou, mesmo, permitindo liberdade de definição para as áreas secas, num misto de flexibilidade planejada e flexibilidade permitida;

- grupo 3: completa liberdade para definição do layout interno. Neste caso, apenas o perímetro com a posição das janelas é fornecido. O layout completo é definido pelo cliente com seu próprio arquiteto. Este formato geralmente ocorre em apartamentos de alto luxo e grande área. Não pode ser considerado um caso de flexibilidade planejada, a menos que haja fixação prévia das prumadas das instalações. Sabe-se que, na prática, os empreendedores acabam por elaborar uma planta básica (inicial) que passa a ser então modificada por cada cliente, recaindo, assim, no caso da flexibilidade permitida;

- grupo 4: junção ou desmembramento de apartamentos contíguos. Podem ocorrer de duas formas: (1) no mesmo pavimento, através de junção ou desmembramento; 
e, (2) em pavimentos diferentes, porém subseqüentes, formando um duplex a partir de dois apartamentos que estejam na mesma prumada.

Desta forma, a flexibilidade arquitetônica é uma modalidade que permite a aplicação da customização em massa nas edificações.

Em outro trabalho, mais recente, Brandão \& Heineck (2007), argumentam que, com as demandas que estão surgindo, e que exigem atendimentos cada vez mais personalizados, a flexibilidade não poderá mais ser encarada de forma reativa por parte das empresas de construção e deverá ter mais relevância a cada dia. Segundo eles, custo e qualidade foram os objetivos de desempenho que se consolidaram com mais solidez na construção, mas a flexibilidade também deverá assumir um papel de importância no sistema de produção.

De fato, estes autores mencionam que o setor de construção de edifícios residenciais continua buscando conciliar o oferecimento de opções ao comprador e atendimento do cliente através de plantas flexíveis e personalização, com a procura também de garantir os aspectos de construção racionalizada. Tal equilíbrio de interesses pode ser obtido mediante uma flexibilidade planejada.

Por sua vez, Yamamoto (2001) descreve, de forma objetiva, como as empresas brasileiras do setor tem proporcionado a customização do imóvel aos compradores, tornando esta possibilidade viável economicamente durante a fase de construção. Atualmente, existem três formas utilizadas pelas construtoras, segundo este autor:

- plantas abertas, ou laje livre: modelo que sugere alguns projetos, mas o cliente pode elaborar o seu com outra distribuição e outros acabamentos diferentes dos padronizados;

- alternativas de plantas: estratégia utilizada por empresas que não são tão flexíveis. Num mesmo empreendimento existem apartamentos do mesmo tamanho, mas com números de quartos diferentes;

- negociação de pequenas alterações: no caso das empresas que não oferecem as alternativas anteriores.

Esta divisão proposta por Yamamoto (2001) tem estreita correlação com as formas de flexibilidade classificadas em quatro grupos distintos por Brandão \& Heineck (1997).

As mudanças implantadas nos projetos, geralmente não modificam o valor do imóvel, uma vez que o valor se baseia na área. No entanto a preferência por determinado layout específico, como a limitação do número de quartos, por exemplo, tendem a limitar 
também o número de interessados na aquisição futura do imóvel, pelo fato de se ter que encontrar um potencial comprador com perfil semelhante (MEDINA; BARACUHY, 2002). Neste sentido, Brandão (2002a) relaciona quatro tipos de modificações que customizam muito o imóvel e que podem dificultar sua venda. Estas modificações são:

- eliminar o banheiro de empregada;

- eliminar toda a divisão entre a sala de estar e a cozinha. Optar por um passapratos;

- trocar os revestimentos originais por outros bem mais caros ou bem mais baratos. O ideal é manter o padrão de acabamento do imóvel;

- eliminar muitos quartos. Dar preferência a mudanças reversíveis.

Segundo Rocha, Heineck, Rodrigues \& Pereira (2004), as alterações de projetos na fase de construção, para adaptações às solicitações dos clientes, podem trazer dificuldades também no planejamento da produção. Para facilitar o processo, o oferecimento de opções previstas e controladas pode ser a solução. Neste caso, é preciso se utilizar de um programa de computador para efetuar o cálculo dos custos adicionais de acordo com as especificações do cliente, além de se estabelecer data-limite para que as especificações sejam definidas.

Do ponto de vista das inovações tecnológicas, Santana, Oliveira \& Meira (2007) citam Brandão (2002), para quem as lajes planas sem vigas, a utilização de shafts para instalações e paredes em chapas de gesso acartonado são exemplos de inovações, capazes de facilitar os procedimentos de flexibilização.

A flexibilidade também está ligada ao princípio de independência entre a estrutura e os elementos de divisão interna (LARCHER, 2005). Dentre os elementos que compõem a estrutura, a laje merece destaque, uma vez que o tipo de laje utilizado interfere diretamente na flexibilidade do projeto.

A escolha do tipo de laje a ser executado numa edificação depende de fatores diversos como segurança e custo. Depende também da finalidade da edificação, tendo por base as propriedades específicas de cada tipo de laje.

Dos diversos tipos de lajes existentes, dois são bastante utilizados em edificações: lajes maciças e lajes nervuradas.

Lajes maciças predominam em obras com vãos relativamente pequenos. Neste caso, as paredes sobre a laje precisam ficar apoiadas nos vigamentos. Isto limita drasticamente as possibilidades de modificação nas plantas. 
Lajes nervuradas, por outro lado, permitem uma redução substancial do peso da própria laje, pela ausência de concreto nos espaços entre as nervuras. Eventualmente pode-se preencher estes espaços com material de baixa densidade, geralmente isopor (ARAÚJO, 2003). Ao se empregar este tipo de laje, se estabelecem duas possibilidades importantíssimas e que facilitam a customização das edificações: grandes vãos livres sem a presença de pilares e livre demarcação de paredes internas (pela não necessidade de apoio das paredes sobre os vigamentos).

Dessa forma, a utilização de lajes nervuradas nas edificações permite um alto grau de flexibilidade, e, portanto, de customização das unidades, pela possibilidade de livre alteração nas plantas padronizadas.

Apesar de toda a importância estratégica da customização de unidades residenciais em edificações verticais, Santana, Oliveira \& Meira (2008), detectaram, em pesquisa realizada na cidade de João Pessoa, que grande parte das construtoras, embora preparadas do ponto de vista técnico para prover a personalização, sequer informam aos seus clientes desta possibilidade. Postura esta que deverá mudar, pelo acirramento da concorrência e pela maturidade do mercado.

\section{RESULTADOS}

Este item traz os resultados obtidos com a pesquisa efetuada e os comentários pertinentes.

O quadro 1 mostra algumas informações com o objetivo de trazer uma visão geral sobre cada uma das empresas pesquisadas. São dados referentes a aspectos como número de empregados, atividades das empresas, etc., representativos da dimensão de cada empresa pesquisada. As obras pesquisadas são todas edificações residenciais, localizadas na cidade de Campina Grande, Estado da Paraíba, cujas características principais estão descritas no quadro 2 . 


\begin{tabular}{|c|c|c|c|}
\hline & A & B & C \\
\hline Porte & pequeno & pequeno & pequeno \\
\hline $\begin{array}{c}\text { N. de empregados } \\
\text { (processo construtivo) }\end{array}$ & 60 & 50 & 20 a 30 \\
\hline $\begin{array}{c}\text { N. de empregados } \\
\text { (gestão) }\end{array}$ & 8 & 10 & sim \\
\hline $\begin{array}{c}\text { Pertence a gnupo } \\
\text { empresanial? }\end{array}$ & não & não & mamoraria \\
\hline Outras atividades & - & - & 15 anos \\
\hline Tempo de atuação & 15 anos & 8 anos & 7 edifícios (10-16 \\
\hline $\begin{array}{c}\text { Outros } \\
\text { empreendimentos }\end{array}$ & 3 edifícios & - & edificações \\
\hline Atividade principal & edficações & edificações & Nordeste \\
\hline Regiões onde atua & Nordeste & Nordeste & Pessoa \\
\hline Cidades onde atua & Campina Grande, João & Campina Grande & $\begin{array}{c}\text { Campina Grande e João } \\
\text { Pessca, Natal }\end{array}$ \\
\hline Certificação & não & não & não \\
\hline Está buscando? & sim & não & não \\
\hline
\end{tabular}

Quadro 1- Dados gerais das empresas

Fonte: Pesquisa direta.

Foi unânime a constatação de que a utilização da customização em massa para a edificação de apartamentos residenciais se deu como uma reação à exigência dos consumidores, embora esta forma de construção seja responsável por um substancial acréscimo no custo final dos empreendimentos.

\begin{tabular}{|c|c|c|c|}
\hline & A & B & C \\
\hline Tipo de Condomínio & Residencial & Residencial & Residencial \\
\hline Forma de Administração & Incorporação & Condomínio & Condomínio \\
\hline Propriedade do Terreno & Construtora & Condomínio & $\begin{array}{c}\text { Condomínio } \\
\text { (permuta em 1 unidade) }\end{array}$ \\
\hline $\mathrm{N}^{\circ}$. Pavimentos & 18 & 21 & 12 \\
\hline $\mathrm{N}^{\circ}$. Andares & 16 & 17 & 10 \\
\hline Unidades/andar & 4 (último:2) & 1 (1 duplex) & 2 \\
\hline Total de unidades & 62 & 16 & 20 \\
\hline Cidade & Campina Grande & Campina Grande & Campina Grande \\
\hline Bairro & Catolé & Mirante & Alto Branco \\
\hline Tipo de laje & nervurada & nervurada & maciça \\
\hline
\end{tabular}

Quadro 2 - Dados gerais dos empreendimentos

Fonte: Pesquisa direta.

Do lado do agente executor, a customização em massa provoca um aumento considerável da complexidade do processo construtivo. No entanto, ambos os argumentos não são suficientes para impedir que se utilize a customização em massa cada vez mais. A possibilidade de alteração nas características dos imóveis se constitui num argumento capaz de diminuir a resistência à compra. 
Além disso, outros fatores foram citados:

- A: exigência cada vez maior do público; procura por modernização; estratégia para agregar valor e diferenciar de outros empreendimentos;

- B: exigências advindas do alto poder aquisitivo dos clientes;

- C: decisão em assembléia; flexibilidade para o cliente; importante argumento de vendas.

\begin{tabular}{|c|c|c|c|c|}
\hline $\begin{array}{c}\text { Flexibilidade } \\
\text { Empreendimento }\end{array}$ & INICIAL & CONTÍNUA & PERMITIDA & PLANEJADA \\
\hline $\mathbf{A}$ & $\mathbf{X}$ & & $\mathbf{X}$ & $\mathbf{X}$ \\
\hline $\mathbf{B}$ & & & $\mathbf{X}$ & \\
\hline $\mathbf{C}$ & & $\mathbf{X}$ & & $\mathbf{X}$ \\
\hline
\end{tabular}

Quadro 3 - Tipo de flexibilidade praticado em cada empreendimento

Fonte: Pesquisa direta baseada em Brandão \& Heineck (1997)

O quadro 3, por sua vez, relaciona o tipo de flexibilidade praticado em cada empreendimento com aqueles descritos por Brandão \& Heineck (1997) no item 2.2 deste trabalho.

O quadro 4 se baseia nas formas de flexibilidade propostas por Brandão \& Heineck (1997), e situa cada empreendimento de acordo com as formas de flexibilidade oferecidas.

\begin{tabular}{|c|c|c|c|c|}
\hline $\begin{array}{c}\text { Formas de Flexibilidade } \\
\text { Empreendimento }\end{array}$ & $\begin{array}{c}\text { Vários apartamentos- } \\
\text { tipo }\end{array}$ & $\begin{array}{c}\text { Vários layouts para } \\
\text { cada apart-tipo }\end{array}$ & $\begin{array}{c}\text { Liberdade de layout } \\
\text { interno }\end{array}$ & $\begin{array}{c}\text { Junção ou } \\
\text { desmembramento }\end{array}$ \\
\hline $\mathbf{A}$ & $\mathbf{X}$ & $\mathbf{X}$ & $\mathbf{X}$ & $\mathbf{X}$ \\
\hline $\mathbf{B}$ & & & $\mathbf{X}$ & $\mathbf{X}$ \\
\hline $\mathbf{C}$ & & $\mathbf{X}$ & & \\
\hline
\end{tabular}

Quadro 4 - Forma de flexibilidade disponível em cada empreendimento

Fonte: Pesquisa direta baseada em Brandão \& Heineck (1997)

A forma de personalização de cada empreendimento de acordo com a proposta de Yamamoto (2001) está descrita no quadro 5.

\begin{tabular}{|c|c|c|c|}
\hline Empreendimento & Plantas abertas & Alternativas de plantas & $\begin{array}{c}\text { Negociação de } \\
\text { pequenas alterações }\end{array}$ \\
\hline A & $\mathbf{X}$ & $\mathbf{X}$ & \\
\hline B & $\mathbf{X}$ & & \\
\hline C & & $\mathbf{X}$ & $\mathbf{X}$ \\
\hline
\end{tabular}

Quadro 5 - Forma de personalização de cada empreendimento

Fonte: Pesquisa direta baseada em Yamamoto (2001)

Os três últimos quadros mostram que todos os tipos e formas de flexibilidade, bem como todas as formas de personalização descritas por Brandão \& Heineck (1997) e por Yamamoto (2001) estavam presentes nas obras pesquisadas. 


\subsection{Localização dos pontos de desacoplamento (DP)}

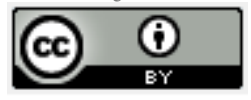

O ponto de desacoplamento (DP) é o ponto, no processo produtivo, onde as especificações dos clientes são consideradas. É onde começa, de forma efetiva, a customização do produto. Ele é importante porque divide o processo construtivo em dois, com características distintas, conforme descrito no item 2.

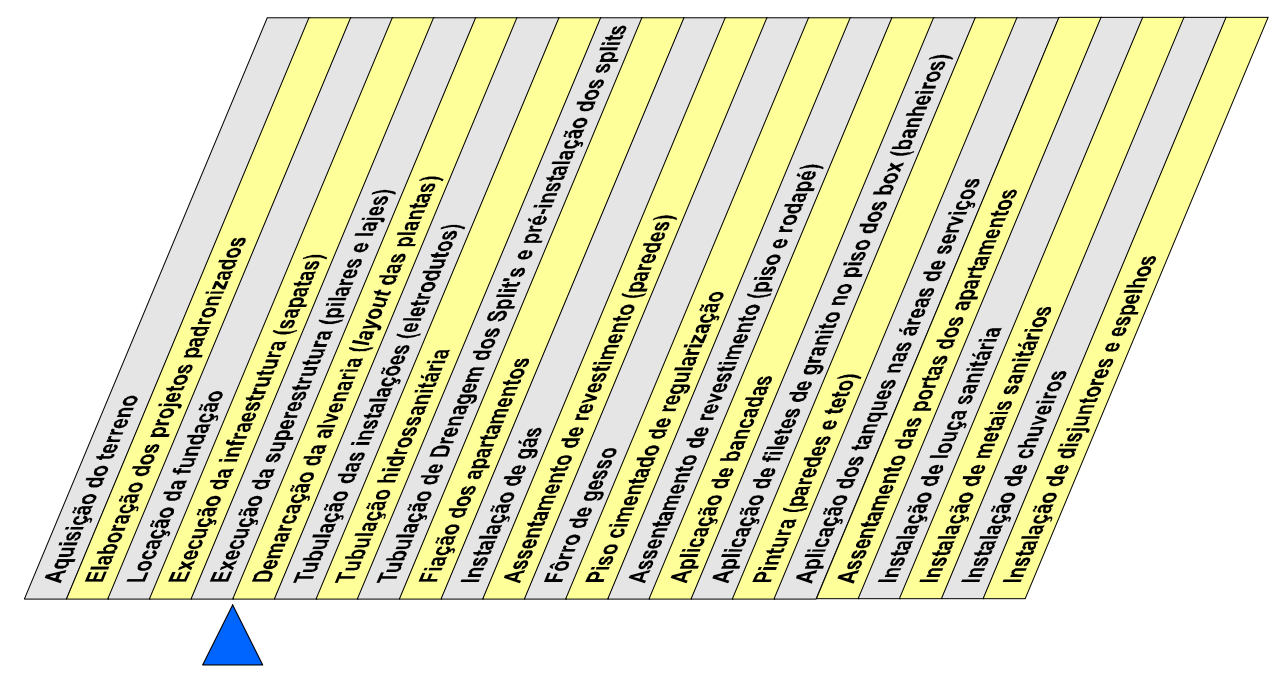

Figura 1 - Localização do ponto de desacoplamento (DP) nos três empreendimentos Fonte: Pesquisa direta.

A figura 1 mostra a localização do ponto de desacoplamento (DP) para os três empreendimentos. Nos três empreendimentos, o ponto de desacoplamento encontra-se no mesmo local: imediatamente antes do início da demarcação das paredes internas (alvenaria).

Como nem todos os clientes utilizam o direito de optar em todas as etapas possíveis, os graus (ou níveis) de customização final de cada unidade podem ser diferentes entre si, embora estejam dentro do mesmo empreendimento. Isto leva a aceitar o ponto de desacoplamento não onde as especificações foram efetivamente levadas em conta, mas onde a estrutura produtiva estava apta a recebê-las, apesar de alguns declinarem desta prerrogativa.

Outra consideração importante é que, por este critério, empreendimentos diferentes, com graus de customização diferentes, tem a mesma localização do ponto de desacoplamento. Isto se dá porque o critério de ponto de desacoplamento leva em consideração apenas a etapa da construção onde o cliente pode exercer suas escolhas, mas desconsidera o número de opções, ou seja, a "profundidade" ou o grau de liberdade destas escolhas. Por este motivo, o ponto de desacoplamento é um mecanismo limitado para determinar o grau de customização de uma obra. 


\section{Revista Produç@̃}

\subsection{Etapas customizáveis}

A partir deste ponto serão detalhadas as etapas customizáveis observadas nos empreendimentos:

- Demarcação da alvenaria (layout das plantas): detalhamento no quadro 6.

\begin{tabular}{|c|c|c|c|}
\hline & $\mathbf{A}$ & B & C \\
\hline Opções oferecidas & $3(104 \mathrm{~m} 2), 3(124 \mathrm{~m} 2)$ & planta única (330 m2) & $3(186 \mathrm{~m} 2)$ \\
\hline $\begin{array}{c}\text { Alternativas para } \\
\text { mudanças }\end{array}$ & livre & livre & Pequenas modificações \\
\hline Limitações & $\begin{array}{l}\text { Áreas técnicas: } \\
\text { prumadas, shafts }\end{array}$ & $\begin{array}{c}\text { Áreas técnicas e áreas } \\
\text { molhadas }\end{array}$ & $\begin{array}{l}\text { Utilizar layout padrão } \\
\text { como base }\end{array}$ \\
\hline Hall social & $\begin{array}{l}\text { Todos padronizados } \\
\text { (critério da construtora) }\end{array}$ & $\begin{array}{l}\text { Todos padronizados } \\
\text { (critério do condomínio) }\end{array}$ & $\begin{array}{l}\text { Customizados por andar } \\
\text { (critério dos } 2 \\
\text { proprietários) }\end{array}$ \\
\hline Percentual custom & $50 \%$ & $100 \%$ & $40 \%$ \\
\hline Fornec. Informação & Proj. arquitetônico & Proj. arquitetônico & $\begin{array}{c}\text { Proj. arquitetônico (base: } \\
\text { original) }\end{array}$ \\
\hline $\begin{array}{c}\text { Prazo para fornecer as } \\
\text { informações }\end{array}$ & $\begin{array}{c}15-60 \text { dias (cronograma } \\
\text { e disponibildade mão-de- } \\
\text { obra) }\end{array}$ & 90 dias, após assembléia & $\begin{array}{l}180 \text { dias para todas as } \\
\text { modificações (assembléia) }\end{array}$ \\
\hline Custos & $\begin{array}{l}\text { Cliente (adicional em } \\
\text { relação à quantidade de } \\
\text { m2 padrão) }\end{array}$ & $\begin{array}{l}\text { Cliente (adicional em } \\
\text { relação à quantidade de } \\
\text { m2 padrão) }\end{array}$ & Não tem custo adicional \\
\hline Execução & Construtora & Construtora & Construtora \\
\hline
\end{tabular}

Quadro 6 - A demarcação das paredes de alvenaria, de acordo com o layout das plantas Fonte: Pesquisa direta

- Tubulação das instalações (eletrodutos): detalhamento no quadro 7.

\begin{tabular}{|c|c|c|c|}
\hline & A & B & C \\
\hline Opções oferecidas & 3 (104m2), 3 (124m2) & planta única & (186 2$)$ \\
\hline $\begin{array}{c}\text { Alternativas para os } \\
\text { clientes }\end{array}$ & $\begin{array}{c}\text { Livre localização dos pontos de: iluminação, tomadas, interruptores, antena, } \\
\text { internet, som. Tamanho das caixas também pode mudar (padrão 4x2) }\end{array}$ \\
\hline Limitações & \multicolumn{3}{|c|}{ Não tem } \\
\hline Fornec. Informação & \multicolumn{2}{|c|}{ Proj. elétrico } \\
\hline Custos & \multicolumn{2}{|c|}{ Construtora paga número de pontos excedentes } \\
\hline Execução & \multicolumn{2}{|c|}{} \\
\hline
\end{tabular}

Quadro 7 - Tubulação das instalações elétricas: detalhamento

Fonte: Pesquisa direta.

- Tubulação hidrossanitária: detalhamento no quadro 8.

\begin{tabular}{|c|c|c|c|}
\hline & A & B & C \\
\hline Opções oferecidas & 3 (104m2), 3 (124m2) & planta única & (186 m2) \\
\hline $\begin{array}{c}\text { Alternativas para os } \\
\text { clientes }\end{array}$ & \multicolumn{2}{|c|}{ Livre localização dos pontos de água e esgoto } \\
\hline Limitações & \multicolumn{2}{|c|}{ Não tem } \\
\hline Fornec. Informação & \multicolumn{2}{|c|}{ Proj. hidrossanitário } \\
\hline Custos & \multicolumn{2}{|c|}{ Cliente paga diferença em relação ao projeto padrão } \\
\hline Execução & \multicolumn{2}{|c|}{ Construtora } \\
\hline
\end{tabular}

Quadro 8 - Tubulação hidrossanitária: detalhamento

Fonte: Pesquisa direta. 


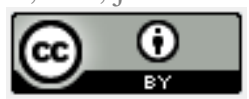

- Tubulação de drenagem e pré-instalação dos splits: detalhamento no quadro 9.

\begin{tabular}{|c|c|c|c|}
\hline & A & B & C \\
\hline Opções oferecidas & 3(104m2), 3 (124m2) & planta única & Caixas de ar condicionado \\
\hline $\begin{array}{c}\text { Alternativas para os } \\
\text { clientes }\end{array}$ & Livre localização dos pontos & Não oferece \\
\hline Limitações & \multicolumn{2}{|c|}{ Não tem } & - \\
\hline Fornec. Inform ação & Proj. elétrico ou arquitetônico & - \\
\hline Custos & Cliente paga diferença em relação ao projeto padrão & - \\
\hline Execução & Construtora & - \\
\hline
\end{tabular}

Quadro 9 - Tubulação de drenagem e pré-instalação dos splits: detalhamento

Fonte: Pesquisa direta.

- Instalação de gás: detalhamento no quadro 10.

\begin{tabular}{|c|c|c|c|}
\hline & A & B & C \\
\hline Opções oferecidas & $3(104 \mathrm{~m} 2), 3(124 \mathrm{~m} 2)$ & planta única & $3(186 \mathrm{~m} 2)$ \\
\hline $\begin{array}{c}\text { Alternativas para os } \\
\text { clientes }\end{array}$ & \multicolumn{3}{|c|}{ Livre (quantidade e localização) } \\
\hline Limitações & \multicolumn{2}{|c|}{ Não tem } \\
\hline Fornec. Informação & \multicolumn{2}{|c|}{ Proj. arquitetônico } \\
\hline Custos & \multicolumn{2}{|c|}{ Cliente paga diferença em relação ao projeto padrão } \\
\hline Execução & \multicolumn{2}{|c|}{ Construtora } \\
\hline
\end{tabular}

Quadro 10 - Instalação dos pontos de gás: detalhamento

Fonte: Pesquisa direta.

- Revestimento de paredes: detalhamento no quadro 11.

\begin{tabular}{|c|c|c|c|}
\hline & $\mathbf{A}$ & B & $\mathrm{C}$ \\
\hline Opções oferecidas & Cerâm ica $30 \times 40$ & Não oferece & Cerâmica padrão \\
\hline $\begin{array}{c}\text { A lternativas para } \\
\text { mudanças }\end{array}$ & \multicolumn{3}{|c|}{$\begin{array}{l}\text { Livre: } \\
\text { - Cerâmica, cerâmica vitrificada, porcelanato, pastilha, durafloor } \\
\text { - Mármore e granito } \\
\text { - Madeira } \\
\text { Variações: tipo, tamanho, espessura, formato, cor, resistência, estampa, } \\
\text { esmalte, polimento, paginação }\end{array}$} \\
\hline Lim itações & nenhuma & nenhuma & nenhuma \\
\hline Percentual customizado & $80 \%$ & $100 \%$ & $40 \%$ \\
\hline Fornec. Inform ação & \multicolumn{3}{|c|}{ Proj. de detalhamento de revestimento e piso (paginação) } \\
\hline Aquisição & Cliente & Cliente ou empresa & Cliente \\
\hline Custo de aquisição & Cliente (diferença) & Cliente & Cliente (diferença) \\
\hline A plicação & Cliente ou empresa & Cliente ou empresa & Só empresa \\
\hline Custo de aplicação & Cliente (diferença) & Cliente & Cliente (diferença) \\
\hline Fornecedores & $\begin{array}{l}\text { Locais, Representantes } \\
\text { locais }\end{array}$ & $\begin{array}{c}\text { Locais, Santa Catarina } \\
\text { (cerâmica) }\end{array}$ & Locais \\
\hline Estocagem & Própria unidade & Depósito & Própria unidade \\
\hline
\end{tabular}

Quadro 11 - Revestimento de paredes: detalhamento

Fonte: Pesquisa direta.

- $\quad$ Forro de gesso: detalhamento no quadro 12. 


\begin{tabular}{|c|c|c|c|}
\hline & A & B & C \\
\hline Opções oferecidas & $\begin{array}{l}\text { Forro liso com junta de } \\
\text { dilatação }\end{array}$ & $\begin{array}{c}\text { Modelo único (pavimento- } \\
\text { tipo) }\end{array}$ & 3 modelos \\
\hline $\begin{array}{l}\text { A lternativas para } \\
\text { mudanças }\end{array}$ & \multicolumn{3}{|c|}{$\begin{array}{l}\text { Livre: tamanhos, formatos, desenhos, sancas, juntas de dilatação, com fibra de } \\
\text { vidro }\end{array}$} \\
\hline Lim itações & nenhuma & nenhuma & nenhuma \\
\hline Percentual custom & $90 \%$ & $100 \%$ & $20 \%$ \\
\hline Fornec. Inform ação & \multicolumn{3}{|c|}{ Proj. de detalhamento (gesso e luz) } \\
\hline Aquisição & Cliente ou empresa & Cliente ou empresa & Cliente ou empresa \\
\hline Custo de aquisição & Cliente (diferença) & Cliente (diferença) & Cliente (diferença) \\
\hline A plic ação & Cliente ou empresa & Cliente ou empresa & Só empresa \\
\hline Custo de aplicação & Cliente (diferença) & Cliente (diferença) & Cliente (diferença) \\
\hline Fornecedores & $\begin{array}{l}\text { Locais e de Araripina } \\
\text { (PE) }\end{array}$ & Locais e de Araripina (PE) & Locais \\
\hline Estocagem & Própria unidade & Recebe na hora de aplicar & Própria unidade \\
\hline
\end{tabular}

Quadro 12 - Forro de gesso: detalhamento

Fonte: Pesquisa direta.

- Revestimento de piso e rodapé: detalhamento no quadro 13.

\begin{tabular}{|c|c|c|c|}
\hline & A & B & C \\
\hline Opções oferecidas & Cerâmica 40 x 40 & Não oferece & Cerâmica padrão \\
\hline $\begin{array}{c}\text { Alternativas para } \\
\text { mudanças }\end{array}$ & \multicolumn{3}{|c|}{$\begin{array}{l}\text { Livre: } \\
\text { - Cerâmica, cerâmica vitrificada, porcelanato, pastilha, durafloor } \\
\text { - Mármore e granito } \\
\text { - Madeira } \\
\text { Variações: tipo, tamanho, espessura, formato, cor, resistência, estampa, } \\
\text { esmalte, polimento, paginação }\end{array}$} \\
\hline Limitações & nenhuma & nenhuma & nenhuma \\
\hline Rodapé & Embutido ou sacado & Embutido ou sacado & Embutido ou sacado \\
\hline Percentual custom & $80 \%$ & $100 \%$ & $40 \%$ \\
\hline Fornec. Informação & \multicolumn{3}{|c|}{ Proj. de detalhamento de revestimento e piso (paginação) } \\
\hline Aquisição & Cliente & Cliente ou empresa & Cliente \\
\hline Custo de aquisição & Cliente (diferença) & Cliente & Cliente (diferença) \\
\hline Aplicação & Cliente ou empresa & Cliente ou empresa & Só empresa \\
\hline Custo de aplicação & Cliente (diferença) & Cliente & Cliente (diferença) \\
\hline Fornecedores & $\begin{array}{l}\text { Locais, Representantes } \\
\text { locais }\end{array}$ & $\begin{array}{c}\text { Locais, Santa Catarina } \\
\text { (cerâmica) }\end{array}$ & Locais \\
\hline Estocagem & Própria unidade & Depósito & Própria unidade \\
\hline
\end{tabular}

Quadro 13 - Revestimento de piso e rodapé: detalhamento

Fonte: Pesquisa direta.

- Aplicação de bancadas: detalhamento no quadro 14.

\begin{tabular}{|c|c|c|c|}
\hline & $\mathbf{A}$ & B & C \\
\hline Opções oferecidas & 1 modelo & Não oferece & 1 modelo \\
\hline $\begin{array}{c}\text { Alternativas para } \\
\text { mudanças }\end{array}$ & \multicolumn{3}{|c|}{$\begin{array}{l}\text { Livre: } \\
\text { Granito, mármore glass, vidro } \\
\text { Variações: tipo, espessura, formato, cor, resistência, textura }\end{array}$} \\
\hline Limitações & tamanho & tamanho & tamanho \\
\hline Percentual custom & $80 \%$ & $100 \%$ & $40 \%$ \\
\hline Fornec. Inform ação & \multicolumn{3}{|c|}{ Proj. de granitos e bancadas } \\
\hline Aquisição & Cliente & Cliente ou empresa & Cliente \\
\hline Custo de aquisição & Cliente (diferença) & Cliente & Cliente (diferença) \\
\hline Aplicação & Cliente ou empresa & Empresa & Só empresa \\
\hline Custo de aplicação & Cliente (diferença) & Cliente & Cliente (diferença) \\
\hline Fornecedores & Locais & Locais & Locais \\
\hline Estocagem & Própria unidade & Depósito & Própria unidade \\
\hline
\end{tabular}

Quadro 14 - Aplicação de bancadas: detalhamento

Fonte: Pesquisa direta. 
- Pintura (paredes e teto): detalhamento no quadro 15.

\begin{tabular}{|c|c|c|c|}
\hline & $\mathbf{A}$ & B & C \\
\hline Opções oferecidas & 1 cor, 1 tipo de tinta & Não oferece & 1 demão básica \\
\hline $\begin{array}{c}\text { Alternativas para } \\
\text { mudanças }\end{array}$ & \multicolumn{3}{|c|}{ Livre: textura, cor, tipo de tinta, papel de parede } \\
\hline Limitações & nenhuma & nenhuma & nenhuma \\
\hline Percentual custom & $90 \%$ & $100 \%$ & $100 \%$ \\
\hline Fornec. Informação & \multicolumn{3}{|c|}{ Proj. de detalhamento } \\
\hline Aquisição & Cliente ou empresa & Cliente ou empresa & Cliente \\
\hline Custo de aquisição & Cliente (diferença) & Cliente & Cliente \\
\hline Aplicação & Cliente ou empresa & Cliente & Só empresa \\
\hline Custo de aplicação & Cliente (diferença) & Cliente & Cliente (diferença) \\
\hline Fornecedores & Locais & Locais & Locais \\
\hline Estocagem & Própria unidade & Depósito & Própria unidade \\
\hline
\end{tabular}

Quadro 15 - Pintura (paredes e teto): detalhamento

Fonte: Pesquisa direta.

- Aplicação dos tanques nas áreas de serviços: detalhamento no quadro 16.

\begin{tabular}{|c|c|c|c|}
\hline & \multicolumn{1}{|c|}{ A } & \multicolumn{1}{c|}{ B } \\
\hline Opções oferecidas & \multicolumn{1}{|c|}{ 1 modelo } & Não oferece & 1 modelo \\
\hline $\begin{array}{c}\text { Alternativas para } \\
\text { mudanças }\end{array}$ & $\begin{array}{l}\text { Livre: } \\
\text { Metal, louça, pvc, granito, granito sintético } \\
\text { Variações: tipo, formato, cor, resistência }\end{array}$ \\
\hline Limitações & tamanho & tamanho & tamanho \\
\hline Percentual custom & $80 \%$ & $100 \%$ & $40 \%$ \\
\hline Fornec. Informação & \multicolumn{3}{|c|}{ Proj. de granitos e bancadas } \\
\hline Aquisição & Cliente & Cliente ou empresa & Cliente \\
\hline Custo de aquisição & Cliente (diferença) & Cliente & Cliente (diferença) \\
\hline Aplicação & Cliente ou empresa & Cliente ou empresa & Só empresa \\
\hline Custo de aplicação & Cliente (diferença) & Cliente & Cliente (diferença) \\
\hline Fornecedores & Locais & Locais & Locais \\
\hline Estocagem & Própria unidade & Depósito & Própria unidade \\
\hline
\end{tabular}

Quadro 16 - Aplicação dos tanques nas áreas de serviços: detalhamento

Fonte: Pesquisa direta.

- Assentamento das portas dos apartamentos: detalhamento no quadro 17.

\begin{tabular}{|c|c|c|c|}
\hline & A & B & C \\
\hline Opções oferecidas & $\begin{array}{c}\text { Modelo padrão } \\
\text { (interna e externa) }\end{array}$ & Não oferece & $\begin{array}{c}\text { Modelo padrão } \\
\text { (interna e externa) }\end{array}$ \\
\hline $\begin{array}{c}\text { Alternativas para } \\
\text { mudanças }\end{array}$ & \multicolumn{3}{|c|}{$\begin{array}{l}\text { Livre: } \\
\text { Madeira: pintura, verniz } \\
\text { Vidro: fosco, transparente, jateado, película } \\
\text { Alumínio } \\
\text { (Com ou sem bandeira) }\end{array}$} \\
\hline Limitações & Portas externas & Não tem & $\begin{array}{l}\text { No mesmo andar, } \\
\text { externas iguais }\end{array}$ \\
\hline Percentual custom & $70 \%$ & $100 \%$ & $40 \%$ \\
\hline Fornec. Informação & \multicolumn{3}{|c|}{ Proj. de portas e esquadrias } \\
\hline Aquisição & Cliente & Cliente & Cliente \\
\hline Custo de aquisição & Cliente (diferença) & Cliente & Cliente (diferença) \\
\hline Aplicação & Cliente ou empresa & Cliente ou empresa & Só empresa \\
\hline Custo de aplicação & Cliente (diferença) & Cliente & Cliente (diferença) \\
\hline Fornecedores & Locais & Locais & Locais \\
\hline Estocagem & Própria unidade & Depósito & Própria unidade \\
\hline
\end{tabular}

Quadro 17 - Assentamento das portas dos apartamentos: detalhamento

Fonte: Pesquisa direta. 
- Instalação de louças sanitárias: detalhamento no quadro 18.

\begin{tabular}{|c|c|c|c|}
\hline & $\mathbf{A}$ & B & C \\
\hline Opções oferecidas & $\begin{array}{c}\text { Modelo padrão } \\
\text { (cor branca) }\end{array}$ & Não oferece & $\begin{array}{c}\text { Modelo padrão } \\
\text { (cor branca) }\end{array}$ \\
\hline $\begin{array}{c}\text { Alternativas para } \\
\text { mudanças }\end{array}$ & \multicolumn{3}{|c|}{ Livre: marca, modelo, cor, tipo de caixa } \\
\hline Limitações & $\begin{array}{c}\text { Dimensão da caixa } \\
\text { acoplada }\end{array}$ & Usar caixa acoplada & - \\
\hline Percentual custom & $70 \%$ & $100 \%$ & $30 \%$ \\
\hline Fornec. Informação & \multicolumn{3}{|c|}{ Proj. de detalhamento } \\
\hline Aquisição & Cliente & Cliente ou empresa & Cliente \\
\hline Custo de aquisição & Cliente (diferença) & Cliente & Cliente (diferença) \\
\hline Aplicação & Cliente ou empresa & Empresa & Só empresa \\
\hline Custo de aplicação & Cliente (diferença) & Cliente & Cliente (diferença) \\
\hline Fornecedores & Locais & Locais & Locais \\
\hline Estocagem & Própria unidade & Depósito & Própria unidade \\
\hline
\end{tabular}

Quadro 18 - Instalação de louças sanitárias: detalhamento Fonte: Pesquisa direta.

- Instalação de metais sanitários: detalhamento no quadro 19.

\begin{tabular}{|c|c|c|c|}
\hline & A & B & C \\
\hline Opções oferecidas & Modelo padrão & Não oferece & Modelo padrão \\
\hline $\begin{array}{c}\text { Alternativas para } \\
\text { mudanças }\end{array}$ & \multicolumn{2}{|c|}{ Livre: marca, modelo, cores, linha de produtos } \\
\hline Limitações & Não tem & $\begin{array}{c}\text { Adaptável à base de } \\
\text { registro Deca }\end{array}$ & Não tem \\
\hline Percentual custom & $70 \%$ & \multicolumn{3}{|c|}{$100 \%$} & $30 \%$ \\
\hline Fornec. Informação & & Proj. de detalhamento & \\
\hline Aquisição & Cliente & Cliente ou empresa & Cliente \\
\hline Custo de aquisição & Cliente (diferença) & Cliente & Cliente (diferença) \\
\hline Aplicação & Cliente ou empresa & Empresa & Só empresa \\
\hline Custo de aplicação & Cliente (diferença) & Cliente & Cliente (diferença) \\
\hline Fornecedores & Locais & Locais & Locais \\
\hline Estocagem & Própria unidade & Depósito & Própria unidade \\
\hline
\end{tabular}

Quadro 19 - Instalação de metais sanitários: detalhamento

Fonte: Pesquisa direta.

Nos três empreendimentos pesquisados, a possibilidade de customização foi considerada um diferencial mercadológico capaz de agregar valor ao produto final. Um destes empreendimentos menciona, em seu material de divulgação, tratar-se de algo único, sem igual, excêntrico e exclusivo. Mesmo que o cliente abra mão desta possibilidade, a personalização é considerada um fator positivo e digno de divulgação. Por isto, havia uma divulgação extensiva com a finalidade de tornar esta possibilidade conhecida e até incentivada. Isto contrasta fortemente com a postura de outras empresas que, embora aptas à customização, sequer informam aos clientes desta possibilidade, conforme constatado por Santana, Oliveira \& Meira (2008) e já citado no item 2.2. 
Embora se tratassem de empresas distintas e sem vínculos umas com as outras, houve uma impressionante correspondência entre as etapas customizáveis dentro dos empreendimentos, mesmo considerando pequenas diferenças dentro destas etapas. Correspondência semelhante ocorreu com as alternativas disponíveis para os clientes. Foram basicamente as mesmas, com uma ou outra limitação, independentemente do empreendimento. Desta forma, as três praticaram o mesmo tipo de customização. O que trouxe diferenciação significativa foi o poder aquisitivo destes clientes (e consequentemente suas escolhas dentro do leque de opções), o que acabou por levar cada empreendimento para um padrão diferente.

\section{CONSIDERAÇÕES FINAIS}

A customização em massa representa, de alguma forma, uma volta às origens do sistema produtivo. Por ela é possível adequar o produto ao cliente, mesmo que este produto seja, essencialmente, um produto de massa, com características de padronização.

Este trabalho teve, como objetivo, analisar o processo de customização em massa no subsetor de edificações da construção civil, e seus desdobramentos em relação à cadeia de suprimentos.

A partir dos resultados, se deduz que a customização em massa na construção civil é uma tendência crescente, que se iniciou em grandes centros urbanos mas que já é praticada em cidades de menor porte. Esta tendência se contrapõe ao modelo anterior que visava alcançar um produto padrão destinado a um público heterogêneo.

O cliente está agora mais consciente de seu valor, e não deseja um produto acabado e sem personalidade. Ele está cada vez mais disposto a interagir com o meio produtivo, na busca conjunta de obter um produto o mais adequado possível aos seus interesses e necessidades, embora tenha que pagar mais por isso. Desta forma, o produto final assim alcançado apresenta uma maior percepção de qualidade; não necessariamente por conformidade às especificações, mas pela maior adequação ao uso a que se destina.

Estas possibilidades se iniciam já na definição do layout dos apartamentos. Apenas em três empreendimentos pesquisados, é possível encontrar as quatro formas e os quatro tipos de flexibilidade de layouts propostos por Brandão \& Heineck (1997). Isto mostra como os avanços nesta área estão se propagando de maneira rápida. 
Objetivou-se averiguar quais elementos são customizados e como se dá o processo de customização. Foram identificadas quase duas dezenas de etapas customizáveis. Em quase todas, a participação do cliente vai além de simplesmente informar seus requisitos. $\mathrm{O}$ envolvimento direto do cliente é fator decisivo para a efetiva configuração do imóvel de acordo com seus desejos. Este envolvimento carece de um maior acompanhamento técnico, uma vez que nem sempre o cliente tem a habilidade e o conhecimento para decidir sobre questões do processo construtivo que, na maioria das vezes, não faz parte do seu dia-a-dia. É uma parceria, por assim dizer, desigual. As diferenças, no entanto, são resolvidas, de forma que o resultado se expressa na satisfação do cliente. Para isto existem várias configurações de formas de aquisição de materiais e de aplicação destes materiais, conforme visto nos resultados.

Por outro lado, o uso de programa de computadores para receber as especificações do cliente seria de grande ajuda neste processo. Nenhuma das empresas pesquisadas utiliza qualquer tipo de software com este objetivo. Isto traz sobrecarga mútua pelo excesso de contatos e seus desdobramentos, como o cálculo de diferenças a pagar (ou a receber) após cada sessão de escolhas. Esses cálculos são feitos para cada apartamento. Em apenas um empreendimento (A) são 62 unidades em construção.

Além do mais, um sistema de informação permitiria a criação de um banco de dados para referência e consultas, bem como para geração de aprendizado, valioso em lançamentos futuros. Este conhecimento permitiria, por exemplo, incorporar as preferências mais recorrentes, no sentido de se tornarem opções disponíveis em outros empreendimentos (próprios ou de terceiros, se o conhecimento viesse a ser compartilhado). Permitiria, também, a preparação da empresa para atingir uma gama maior de clientes, sem contar com a perspectiva de transformar fornecedores dos clientes em fornecedores da empresa.

Objetivou-se também identificar os aspectos que contribuem para a customização no processo construtivo. Neste sentido, a participação ativa do cliente no processo é, ao mesmo tempo, um dos aspectos que contribuem e ao mesmo tempo dificultam a customização. A dificuldade se relaciona à multiplicação do número de fornecedores, uma vez que os fornecedores de cada cliente são fornecedores da obra. No entanto, este fator poderia ser transformado em benefício, caso cada cliente tornasse seus fornecedores disponíveis para os demais, numa integração quase perfeita da cadeia de suprimentos. Infelizmente, estes 
conceitos são bem explorados na teoria, mas não são correspondidos na prática, pela falta de articulação entre os membros da cadeia.

Por último, se objetivou identificar a utilização da estratégia de postponement na cadeia de suprimentos com a determinação da localização do ponto de desacoplamento para cada empreendimento.

Considerando a história da produção, a customização em massa está em seus primeiros passos. Na construção civil mais ainda. De forma que muito ainda precisa ser explorado e aperfeiçoado, no sentido de trazer maior conhecimento e compreensão sobre a realidade. As maiores contribuições, neste sentido, devem estar voltadas para a entrada, tratamento e posterior uso das informações geradas pela estratégia de customização em massa dos apartamentos. Com tal volume e complexidade de informações, toda tentativa de melhorar o processo e facilitar a administração será muito bem vinda.

\section{REFERÊNCIAS}

ALFNES, E.; STRANDHAGEN, J. O. Enterprise design for mass sustomization: the Control Model Methodology. International Journal of Logistics, v.3, n.2, p.111-125, july, 2000.

ARAUJO, J.M. Curso de concreto armado. 2. ed. Rio Grande: Editora Dunas, 2003. v.2.

BRANDÃO, D. Q. Diversidade e potencial de flexibilidade de arranjos espaciais de apartamentos: uma análise do produto imobiliário no Brasil. 2002. 443f. Tese (Doutorado em Engenharia de Produção)- Universidade Federal de Santa Catarina, Florianópolis, 2002a.

BRANDÃO, D. Q. Personalização do produto habitacional: novas demandas e resposta das tecnologias de construção. In: ENCONTRO NACIONAL DE ENGENHARIA DE PRODUÇÃO, 22, 2002, Curitiba. Anais... Curitiba: PUCPR, 2002 b.

BRANDÃO, D. Q.; HEINECK, L. F. M. Formas de aplicação da flexibilidade arquitetônica em projetos de edifícios residenciais multifamiliares. In: ENCONTRO NACIONAL DE ENGENHARIA DE PRODUÇÃO, 17, Gramado. Anais... Gramado: ABEPRO, PPGEP/UFSC, 1997.

BRANDÃO, D. Q.; HEINECK, L. F. M. Estratégias de flexibilização de projetos residenciais iniciadas na década de 1990 no Brasil: tão somente um recurso mercadológico? Ambiente Construído. Revista on-line da ANTAC, Porto Alegre, v. 7, n. 4, p. 71-87, out./dez. 2007.

CUNHA, D. C.. Avaliação dos resultados da aplicação de postponement em uma grande malharia e confecção de Santa Catarina. 175f. Dissertação (Mestrado em Engenharia de 
Produção) - Programa de Pós-Graduação em Engenharia de Produção, UFSC, Florianópolis, 2002.

DAVIS, S.M. Future perfect. Addison-Wesley, Reading, MA, 1987.

FISHER, M. L. What is the right supply chain for you product? Harvard Business Review. p. 105-116. Mar-Abr, 1997

FONTANINI, P. S. P. Mentalidade enxuta no fluxo de suprimentos da construção civil: aplicação de macro mapeamento na cadeia de fornecedores de esquadrias de alumínio. $259 \mathrm{f}$. Dissertação (Mestrado em Engenharia Civil). Universidade Estadual de Campinas. Campinas, 2004.

FRUTOS, J. D. Desenvolvimento de um sistema de informação para a interação ágil entre clientes e empresas incorporadoras e construtoras de condomínios residenciais. 2000. 152f. Dissertação (Mestrado em Administração de Empresas). Universidade Federal do Rio Grande do Sul. Porto Alegre, dez. 2000.

GIL, A. C..Como elaborar projetos de pesquisa. 3. ed. São Paulo: Altas. 1996. 159 p.

GRAEML, A. R. O valor da tecnologia da informação. In: SIMPÓSIO DE ADMINISTRAÇÃO DA PRODUÇÃ̃O, LOGÍSTICA E OPERAÇÕES INDUSTRIAIS, 1, 1998, São Paulo. Anais... São Paulo: EAESP-FGV, set. 1998.

HAMZAGIC, M. Flexibilidade de produção na montadora e postponement. 2003, 167f. Dissertação (Mestrado em Administração de Empresas). Departamento de Economia, Ciências Contábeis e Administração, Universidade de Taubaté. Taubaté, 2003.

HART, C. W. Mass customization: conceptual underpinnings, opportunities and limits. International Journal of Service Industry Management. Bradford, v. 6, n. 2, p. 36-45, 1995.

JOBIM FILHO, H.; JOBIM, M. S. S.; ESTRADA, R. J. S. Proposta de integração das cadeias de suprimentos da indústria da construção civil através do gerenciamento sustentável. In: ENCONTRO NACIONAL DE ENGENHARIA DE PRODUÇÃO, 22, Curitiba. Anais... Curitiba: PUCPR, 2002.

KOTHA, S. From mass production to mass customization: the case of the national industry bicycle company of Japan. European Management Journal. London, v.14, n.5, p.442-450, out. 1996.

KUMAR, A. From mass customization to mass personalization: a strategic transformation. Flexible Services and Manufacturing, Springer US, v. 19, n. 4, p. 533-547, abr. 2008.

LAMPEL, J.; MINTZBERG, H. Customizing customization. Sloan Management Review. v. 38, p. 21-30, fall, 1996. 
LARCHER, J.V.M. Diretrizes visando à melhoria de projetos e soluções construtivas na expansão de habitações de interesse social. 2005. 119f. Dissertação (Mestrado em Engenharia Civil). Universidade Federal do Paraná, Curitiba, 2005.

LEE, H.; TANG, C. S. Modeling the costs and benefits of delayed product diffrentiation. Management Science, v. 43, n.1, p. 40-53, 1997.

MAIA, J. C. F. A cadeia produtiva na indústria de construção imobiliária: estudo de Caso na cidade do Rio de Janeiro. 2004, 126f. Dissertação (Mestrado em Engenharia Industrial). Pontifícia Universidade Católica do Rio de Janeiro, 2004.

MEDINA, E.; BARACUHY, J. L. "Um galpão com a minha cara”. Arquitetura \& Construção, v. 18, n.2, p.60-67, fev. 2002.

MELO, H. L.; EULALIA, L. A. S.; BREMER, C. F. Postponement: uma prática de supply chain management para possibilitar a customização em massa. In: SIMPÓSIO DE ENGENHARIA DE PRODUÇÃO, 7, 2000. Anais... Bauru: UNESP, 2000.

MENTZER, J. T. et al. Defining supply chain management. Journal of Business Logistics. v.22, n. 2, 2001.

PAGH, J. D.; COOPER, M. C. Supply chain postponement and speculation strategies: how to choose the right Strategy. Journal of Business Logistics, v. 19, n. 2, p. 13-33, 1998.

PILLER, F.; KUMAR, A. For each, their own: the strategic imperative of mass customization. Industrial Engineer, v.38, n.9, p. 40 - 45, set. 2006.

ROCHA, F. E. M. et al. Logística e lógica na construção lean. 1. ed. Fortaleza: Fibra Construções, 2004. v. 1. 152 p.

SANTANA, C.; OLIVEIRA, D.; MEIRA, A. Personalização de imóveis verticais residenciais: um estudo exploratório nas construtoras da cidade de João Pessoa. In: CONGRESSO DE PESQUISA E INOVAÇÃO DA REDE NORTE NORDESTE DE EDUCAÇÃO TECNOLÓGICA, 2. Anais... João Pessoa, PB, 2007.

SANTANA, C. L.; OLIVEIRA, D. N. S.; MEIRA, A. R. Uma análise do sistema de personalização de imóveis residenciais na cidade de João Pessoa. In: ENCONTRO NACIONAL DE TECNOLOGIA DO AMBIENTE CONSTRUÍDO, 12. 7 a 10 de outubro de 2008, Fortaleza, CE, 2008.

SIMCHI-LEVI, D.; KAMINSKY, P.; SIMCHI-LEVI, E. designing and managing the supply chain; concepts, strategies, and case studies. Irwin/McGraw-Hill, 1999.

SVENSSON, G. The theoretical foundation of supply chain management - a functionalist theory of marketing. International Journal of Physical Distribution \& Logistics Management, v. 32, n. 9, 2002. 
SVENSSON, C., BARFORD, A., 2002, "Limits and opportunities in mass customization for 'build to order' SMEs", Computers in Industry, 49, 77-89. 2002.

VAN HOEK, R. I. Logistics and virtual intregration: postponement, outsourcing and the flow of Information. International Journal of Physical Distribuition \& Logistics, v. 28, n. 7, p. $508-523,1998$.

VERGARA, S. C. Projetos e relatórios de pesquisa em administração. 5 ed. São Paulo: Atlas, 2004.

WALLER, M.A.; DABHOLKAR, P.A.; GENTRY, J.J. Postponement, product customization, and market-oriented supply chain management. Journal of Business Logistics, v. 21, n. 2, 2000, p. 133-159.

YAMAMOTO, K. L. Apartamento sob medida. Arquitetura \& Construção, p. 119-122, abr. 2001.

ZEGARRA, S. L. V.; FRIGIERI JR., V. \& CARDOSO, F. F. A tecnologia da informação e a indústria da construção de edifícios. In: SIMPÓSIO BRASILEIRO DE GESTÃO DA QUALIDADE E ORGANIZAÇÃO DO TRABALHO. Anais... Recife: 1999, v.1. 